\title{
Social and Economic Value Evaluation of Water Resource Based on Fuzzy Mathematics and Emergy Theory
}

\author{
Xiang XU ${ }^{\mathrm{a}, \mathrm{b}}$, Yongqiang WANG ${ }^{\mathrm{a}, 1}$, Kai LI ${ }^{\mathrm{a}}$, Junsong XIN ${ }^{\mathrm{b}}$ \\ ${ }^{a}$ Water Resources Department (Transboundary River Management Department), \\ Changjiang River Scientific Research Institute, Wuhan 430010, China and Hubei \\ Provincial Key Laboratory of Basin Water Resources and Ecological Environmental \\ Sciences, Changjiang River Scientific Research Institute, Wuhan 430010, China \\ ${ }^{b}$ College of Hydrology and Water Resources, Hohai University, Nanjing 210098, China
}

\begin{abstract}
Water resources is one of the important drivers of socio-economic development, but the value of water resources in society is not clear. In order to accurately describe the impact of water resources on socio-economic value, a socioeconomic value evaluation index system for water resources is established. This paper is based on the theory of utility value of water resources. Discussed how to use fuzzy mathematics and benefit sharing coefficient method to calculate the socio-economic value of water resources in different industries. Take the Golog Zang A.P in the source region of the Yellow River as an example. Calculated the socio-economic value of water resources for residential life, irrigation planting, industry, construction and tertiary industry. Finally, analysis results show that the value of comprehensive water resources in the study area is between $9.4-40 \mathrm{CNY}$, tertiary industry highest, lowest value for domestic water. The calculation results provide a reference for the rational and efficient use of regional water resources and the scientific formulation of water resources policies.
\end{abstract}

Keywords. Social and economic value, evaluation of water resource, entropy weight method, fuzzy comprehensive evaluation, emergy, benefit sharing coefficient

\section{Introduction}

Water is very important to our lives and society. It is an irreplaceable scarce economic resource for social and economic development, and also the most active and widely influential basic natural resource in the ecosystem. The purpose of this paper is to analyze the social and economic value of water resources for different industries in the region.

1 Corresponding Author: Yongqiang Wang, Water Resources Department (Transboundary River Management Department), Changjiang River Scientific Research Institute, Wuhan 430010, China and Hubei Provincial Key Laboratory of Basin Water Resources and Ecological Environmental Sciences, Changjiang River Scientific Research Institute, Wuhan 430010, China; E-mail: wangyongqiang1022@126.com

This work is funded by the National Key R\&D Program of China (2017YFC0403600, 2017YFC0403606); the National Natural Science Foundation of China (No.51779013, 51639005); the Water Conservancy Science and Technology Innovation project of the GuangDong Province (2017-03); National Public Research Institutes for Basic R\&D Operating Expenses Special Project (No. CKSF2019478, No. CKSF2017008) Special thanks are given to the anonymous reviewers and editors for their constructive comments. 
Establishing evaluation indicators and evaluation models for the socio-economic value of water resources. It can better reflect the actual situation of social and economic benefits of water resources, and provide a reference for the rational and efficient use of water resources.

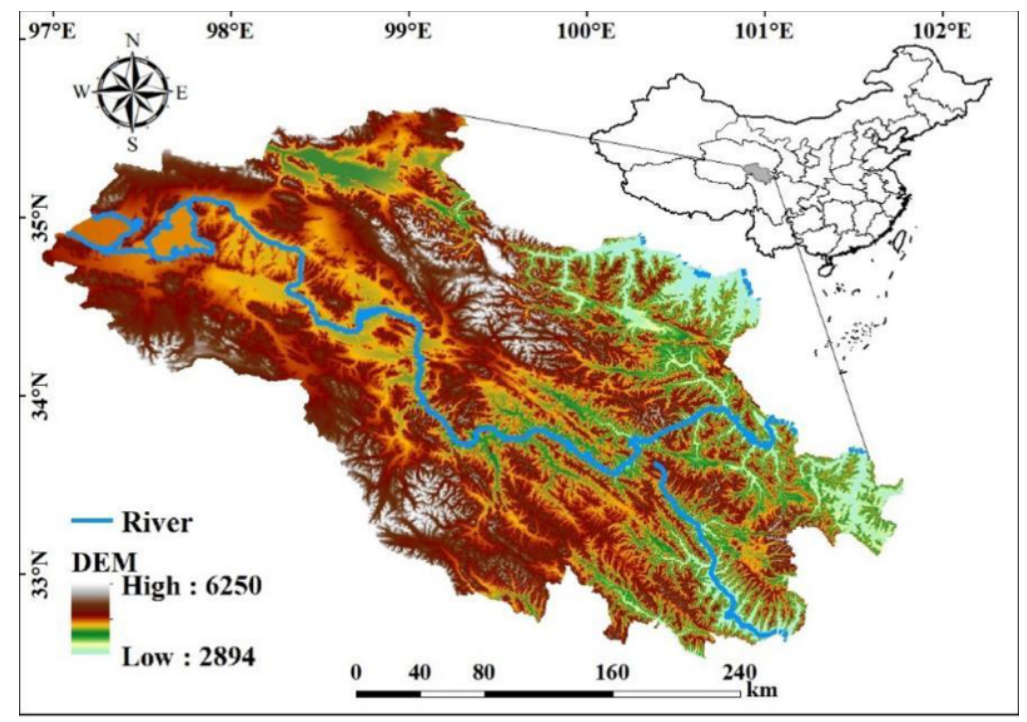

Figure 1. Study area.

To systematically analyze the socio-economic value of water resources. From figure 1. The research area is located in Golog Zang A.P of Qinghai Province, China, which belongs to arid and semi-arid areas in northwest China. By referring to past studies, we can clearly see that most of the study areas are located in economically developed areas, and the regional water resources crisis is more significant. The study of the value of water resources is imminent. However, we can find the current of social development in recent years. Although the social economy of the Northwest has improved, it has brought along a series of problems such as high consumption of water resources, low utilization of water resources, and serious water pollution. At this time, it is even more necessary for us to have a study on the value of local water resources, so that we can systematically realize that the water resources crisis is not a characteristic of economically developed regions, and to have a good understanding of the value of water resources in advance is helpful for us to achieve better sustainable development.

The Golog Zang A.P in Qinghai Province is located between the Bayan Har and Animaqing Mountains in the hinterland of the Qinghai-Tibet Plateau, in the east of the Three Rivers Source Area, Geographically located between $32^{\circ} 21^{\prime}-35^{\circ} 45^{\prime}$ north latitude and $96^{\circ} 56^{\prime}-101^{\circ} 45^{\prime}$ east longitude. The administrative divisions mainly include 6 counties, Maduo, Dari, Gande, Maqin, Jiuzhi and Banma, with a total area of $7.6 \times 104 \mathrm{~km} 2$. The average altitude in the area is above $4200 \mathrm{~m}$, and the climate is a plateau alpine climate, with alternating hot and cold seasons and distinct dry and wet seasons. The average annual temperature is $-4^{\circ} \mathrm{C}$ and the average annual rainfall is $400-700 \mathrm{~mm}$. Grassland is the main vegetation type in this area, accounting for $71 \%$ of the total land area. In 2019 , the prefecture completed a regional GDP of 4,618.35 million yuan, a year-on-year increase of $7.2 \%$, which was three times that of ten years ago. The state's per capita regional product 
value was 2,1990 yuan, a year-on-year increase of 5.22\%. The population accounts for more than $75 \%$ of the total population, and the urbanization rate is $28.02 \%$.

\section{Literature Review and Data Sources}

Since the 1980s, great progress has been made in the research models and methods of water resources value at home and abroad. At present, the commonly used models include the following aspects: (1) Shadow price model. Zhu Jiulong and others[1] use linear programming model to estimate the theoretical value of water resources of different departments in 5 river sections of Huaihe River basin in 2000, taking the maximum net benefit of river basin water use as the objective function; proposed a method and a solution process for calculating the shadow price of water resources by using a nonlinear dynamic input-output optimization model, and calculated the shadow price of water resources in China's nine major watersheds from 1949 to 2050[2].(2) Fuzzy mathematics model. Jiang wenlai [3] estimated the water resources value of Beijing area in 1992 to be $1.041 \mathrm{~m} 3$ by using fuzzy mathematics model, considering the influence of water quality After that, the value of water resources is $1.592 \mathrm{~m}^{3}$; Miao Huiying and others[4] used fuzzy hierarchical mathematical model to make fuzzy comprehensive evaluation on the value of water resources in Shijiazhuang, and got the result that the value of water resources in that year was medium to high. Liu Dezhi used fuzzy comprehensive evaluation model to analyze the value of water resources in Hutuo River basin. Qiu Lin used fuzzy optimization neural network model to evaluate the value of water resources. (3) Residual value model. Renwick[5] estimated the value of Sri Lanka rice planting water as 0.93 Sri Lankan rupees (US\$ $1=100$ Sri Lankan rupees) using the residual value model. Glenn-Marie Lange[6] uses the residual value model in the Stampriet area of Namibia, and estimates the value range of unilateral agricultural water use in 1999 by assuming the rate of return on capital and the value range of land resources. The comprehensive evaluation methods of water resources value mainly include Emergy theory[7], matrix method[8], neural network method, comprehensive index method [9].

To sum up, we consider that the water resources system is a complex system, which is formed under the interaction, coupling and influence of natural, social and economic systems. There are many factors that affect the value of water resources. Each factor is not produced singly, but is interrelated. The value is the result of their joint action, which leads to the fuzziness of value composition and influencing factors. It is therefore unreasonable to consider the value of water resources from only one aspect. Based on the above reasons, we use fuzzy mathematics to calculate the value of water resources corresponding to residents' lives and use the energy value theory to calculate the benefit sharing coefficient, and then obtain the corresponding water industry value.

The socio-economic indicator data required for the study area comes from the National Economic and Development Bulletin of the autonomous prefecture, the government work report and the regional statistical year book (http://tjj.qinghai.gov.cn/tjData/qhtjnj/;http://tjj.qinghai.gov.cn/tjData/yearBulletin/;http:/ /slt.qinghai.gov.cn/subject/list?cid=58). 


\section{Value of Residents' Living Water Resources}

\subsection{Fuzzy Comprehensive Evaluation Model}

\subsubsection{Establishment of Social and Economic Benefit Evaluation Index System}

The evaluation index system of social and economic benefits is an important basis for us to evaluate and judge the rationality of the selected scheme, so we should follow certain principles and standards when establishing the index system to ensure that it can correctly, scientifically, comprehensively and objectively reflect the effect of the evaluation model. The evaluation index system of social and economic benefits of Golog Zang A.P includes two levels: the factor level and the index level[10]. The factor level of this evaluation is divided into two categories of economic benefits $\left(U_{1}\right)$ and social benefits $\left(U_{2}\right)$. Each factor level is further divided into several index levels, as shown in Table 1 for details, thus establishing an index element set $U=\left(U_{1}, U_{2}\right)$.

Table 1. Composition of Index System

\begin{tabular}{|c|c|c|}
\hline Target layer & Element layer & Indicator layer \\
\hline \multirow{2}{*}{$\begin{array}{l}\text { Evaluation of Social } \\
\text { and Economic } \\
\text { Benefits }\end{array}$} & Economic benefits $\left(U_{1}\right)$ & $\begin{array}{l}\text { Per capita disposable income } \\
\text { Output value of agriculture and animal } \\
\text { husbandry } \\
\text { Output Value of Chinese and Tibetan Medicinal } \\
\text { Materials }\end{array}$ \\
\hline & Social benefits $\left(U_{2}\right)$ & $\begin{array}{l}\text { Grassland area } \\
\text { Grassland availability factor } \\
\text { population rate of increase } \\
\text { Number of people out of poverty }\end{array}$ \\
\hline
\end{tabular}

\subsubsection{Data Collection and Selection of Indicators}

Through the analysis and research of the basic data of the Golog Zang A.P, we selected the indicators shown in Table 1. Among the economic benefits, we considered the three indicators of per capita disposable income(E1), agricultural and animal husbandry output(E2), and Chinese and Tibetan medicinal materials(E3). The reason is that Golog Zang A.P is located on the Qinghai-Tibet Plateau in China. The high altitude and low temperature are not conducive to crop growth. The added value of the primary industry mainly comes from the value of animal husbandry. Development and utilization are conducive to increasing the disposable income of people in the region. In terms of social benefits. The four indicators of grassland area(S1), grassland availability factor(S2), population growth rate(S3), and number of people out of poverty(S4) are taken into consideration. We know that Golog Zang A.P belongs to the San jiang yuan Natural Ecological Reserve. The area contains a large number of grassland resources. Grazing is the main source of income for residents. However, in recent years, with the excessive use of grassland and the irrational use of water resources, it has seriously affected the sustainable development of the region's economy. With the increase of the population, these problems will have a greater negative effect on regional stability if they are not reasonably solved. From the indicator of the number of people who are out of poverty, we can clearly see the social and economic development of the region. We cannot judge the size of regional water security problems by the amount of regional water resources. Analyzing and analyzing the benefits of water resources to our economy and society can help us formulate targeted policies to solve a series of problems that arise from this. 
The raw data is shown in the following table. A, B, C, D, E, and F in the table represent Maqin County, Banma County, Gande County, Dari County, Jiuzhi County, and Maduo County, respectively.

Table 2. Indicator Data.

\begin{tabular}{cccccccc}
\hline Area & $\begin{array}{c}\text { E1 } \\
\text { (yuan) }\end{array}$ & $\begin{array}{c}\text { E2 } \\
\left(10^{4} \text { yuan }\right)\end{array}$ & $\begin{array}{c}\text { E3 } \\
\left(10^{4}\right. \\
\text { yuan })\end{array}$ & $\begin{array}{c}\text { S1 } \\
\left(10^{4} \text { hectares }\right)\end{array}$ & $\begin{array}{c}\text { S2 } \\
(\%)\end{array}$ & $\begin{array}{c}\text { S3 } \\
(\%)\end{array}$ & $\begin{array}{c}\text { S4 } \\
\text { (person) }\end{array}$ \\
\hline A & 9834 & 21885.8 & 165.34 & 117.58 & 9 & 11.52 & 1025 \\
B & 11843 & 13107.33 & 157.72 & 39.67 & 85 & 7.15 & 2413 \\
C & 9783 & 13242.18 & 203.65 & 65.12 & 90 & 11.7 & 5715 \\
D & 12266 & 12175.46 & 194.27 & 140.166 & 79 & 13.57 & 4082 \\
E & 9745.69 & 12853.42 & 158.48 & 73.236 & 90 & 12.84 & 2262 \\
F & 15602 & 8295.29 & 226.86 & 229.91 & 79 & 13 & 2698 \\
\hline
\end{tabular}

\subsubsection{Evaluation Methods}

This evaluation uses fuzzy comprehensive evaluation as the evaluation model of social and economic benefits, and uses entropy weight method to calculate the index weight. According to the mathematical principle of fuzzy relation, fuzzy information is quantified through fuzzy information, which can effectively quantify the influencing factors with unclear boundaries and concepts.

\subsubsection{Entropy Weight Method to Calculate Index Weight [11]}

(1) Standardized treatment of evaluation indicators

Among the selected evaluation indicators. There are indicators that have a positive impact on the efficient use of water resources, that is, positive indicators; There are also indicators that have a negative impact on the efficient use of water resources, that is, negative indicators. Therefore, the initial data needs to be standardized for comparability.

For positive indicators, the standardized processing formula is:

$$
X_{i j}=\frac{X_{i j}-\min \left(\mathrm{X}_{\mathrm{ij}}\right)}{\max \left(\mathrm{X}_{i j}\right)-\min \left(\mathrm{X}_{\mathrm{ij}}\right)}
$$

For negative indicators, the standardized processing formula is:

$$
X_{\mathrm{ij}}=\frac{\max \left(\mathrm{X}_{i j}\right)-\mathrm{X}_{i j}}{\max \left(\mathrm{X}_{i j}\right)-\min \left(\mathrm{X}_{i j}\right)}
$$

In the formula: $\mathrm{X}$ is the data in Table $2, \mathrm{i}$ and $\mathrm{j}$ are respectively represented as the $\mathrm{i}$-th row and the $\mathrm{j}$-th column.

(2) Determination of entropy

The entropy value is calculated by the following formula:

$$
\begin{gathered}
H_{i}=-k \sum_{j=1}^{n} f_{i j} \ln f_{i j} \\
f_{i j}=\frac{g_{i j}}{\sum_{j=1}^{n} g_{i j}} \\
k=\frac{1}{\ln n}
\end{gathered}
$$


In the formula: $\mathrm{H}_{\mathrm{i}}$ is the entropy value of evaluation index $\mathrm{I}$, and it is assumed here that when $\mathrm{f}_{\mathrm{ij}}=0, \mathrm{f}_{\mathrm{ij}} \ln \mathrm{f}_{\mathrm{ij}}=0$; $\mathrm{g}_{\mathrm{ij}}$ is the normalized matrix of the original evaluation index, $\mathrm{K}$ is Boltzmann constant, and $\mathrm{n}$ is the total number of research objects. The smaller the entropy value, the more useful information the index can provide for decision makers.

(3) entropy weight of evaluation index

After obtaining the entropy value $\mathrm{H}$, the entropy weight of the evaluation index is determined by the following formula:

$$
\omega_{i}=\frac{1-H_{i}}{m-\sum_{i=1}^{m} H_{i}}\left(0 \leq \omega_{i} \leq 1, \sum_{i=1}^{m} \omega_{i}=1\right)
$$

\subsubsection{Steps to Establish Fuzzy Mathematical Model}

(1) establish fuzzy evaluation matrix

According to Zadeh's groundbreaking research in 1965[12], he proposed the concept of fuzzy sets and Chen Shouyu's fuzzy set theory[13,14]. It is assumed that the system has $\mathrm{n}$ candidate options to form the solution set, and $\mathrm{m}$ indicators to perform the solution set. The set of indicators to be judged, then the eigenvalue matrix of the indicator is

$$
X_{m \times n}=\left[\begin{array}{cccc}
x_{11} & x_{12} & \cdots & x_{1 n} \\
x_{21} & x_{22} & \cdots & x_{2 n} \\
\vdots & \vdots & \cdots & \vdots \\
x_{m 1} & x_{m 2} & \cdots & x_{m n}
\end{array}\right]=\left(x_{i j}\right)_{m \times n}
$$

The fuzzy evaluation matrix can be obtained by evaluating the indexes to determine the membership degree of the evaluation objects to the elements of the evaluation set [15].

$$
\begin{gathered}
R_{\mathrm{i}}=\left[\begin{array}{ccc}
a_{11} & \ldots & a_{1 n} \\
\vdots & \ddots & \vdots \\
a_{m 1} & \cdots & a_{m n}
\end{array}\right] \\
(n=5 ; m=\text { number of indicator })
\end{gathered}
$$

(2) establishing fuzzy comprehensive evaluation

The fuzzy comprehensive evaluation of the corresponding indicators can be obtained through the weight set $\omega_{i}$ and the single-factor evaluation matrix $\mathrm{R}_{i}$ of each indicator.

$$
B_{i}=\omega_{i} \times \mathrm{R}_{i}, \quad \mathrm{i}=1,2
$$

The above evaluation results are regarded as a fuzzy comprehensive evaluation matrix B composed of multiple single-factor evaluation sets, and the evaluation of the benefit is as follows:

(3) Evaluation of results

$$
C=A \times B
$$

It can be known from the above calculation results that the comprehensive evaluation vector of water resources is converted into the price of water resources by the following formula, thereby reflecting the value of water resources. 


$$
W=C \times S^{T}
$$

Where $W$ is the price of water resources and $S^{T}$ is the transposed vector of water resource price vectors, $S=\left(\begin{array}{llllll}P & P_{1} & P_{2} & P_{3} & 0\end{array}\right)$.

The determination of the vector $\mathrm{S}$ uses the method of social affordability. The affordability mentioned in this paper refers specifically to the tolerance of people to accept this fact under the stimulus of rising water prices. In the vector S, P is the upper limit of the water price, that is, the highest tolerable water price. The calculation formula of $\mathrm{P}$ is

$$
\mathrm{P}=\mathrm{BE} / \mathrm{C}-\mathrm{D}
$$

In the above formula, $\mathrm{B}$ is the maximum water fee bearing index (the calculation formula is $\mathrm{B}=$ water fee expenditure/actual income), $\mathrm{E}$ is the actual income of residents, $\mathrm{C}$ is the water consumption of residents, and $\mathrm{D}$ is the cost of water supply and normal profit for tap water.

\section{Result Analysis}

\subsection{Analysis of Basic Data}

By analyzing the data in Table 2 . we can clearly see that Maduo county is in the leading position in Chinese and Tibetan medicinal materials, per capita disposable income and grassland area. But the output value of agriculture and animal husbandry is the lowest. Because the county actively adjusts its industrial structure, the proportion of tertiary industry investment in fixed assets investment reaches $80.2 \%$. Maqin County is at the highest value in agricultural and animal husbandry output value. Gande county and jiuzhi county are both at a high level in grassland availability coefficient. In terms of population growth rate, Dari County has the highest rate, while Gande county has the highest number of people out of poverty. However, comparing various data, it can be clearly found that there is not much difference between counties, which increases the reliability of the evaluation of social and economic benefits in the region. Through per capita disposable income, it can be seen that the region's economy is still backward and the people's living standard needs to be improved.

\subsection{Analysis of Weight Calculation Results}

We process the data in Table 2 and use the above calculation steps to calculate by programming, we can get the following calculation results. The weight calculated by entropy weight method are as follows:

Table 3. Weight calculation results.

\begin{tabular}{ll}
\hline Name & weight \\
\hline Output Value of Chinese and Tibetan Medicinal Materials & 0.347 \\
Output value of agriculture and animal husbandry & 0.196 \\
Per capita disposable income & 0.457 \\
Grassland area & 0.372 \\
Grassland availability factor & 0.166 \\
population rate of increase & 0.174 \\
Number of people out of poverty & 0.288 \\
\hline
\end{tabular}

In economic benefits, from Table 3, agriculture and animal husbandry have the lowest weight, that is, this index has the greatest reference significance, which coincides with the actual situation that agriculture and animal husbandry are the main economic sources of 
local herdsmen in high altitude and low temperature areas, thus increasing the reliability of benefit evaluation. In social benefits, there is little difference in the weight of various indicators. The grassland availability coefficient and population growth rate are relatively low. Among them, the grassland availability coefficient directly affects the grazing area of herdsmen. Population growth rate, as the main reference data to measure the population development in a region, is more valuable for poor regions, reasonably controls the population and avoids vicious circle.

\subsection{Fuzzy Comprehensive Evaluation Results}

The following results can be calculated by Equation 5-8:

Single factor evaluation matrix of economic benefits

$$
R^{1}=\left[\begin{array}{ccccc}
0.2 & 0.4 & 0.3 & 0.1 & 0 \\
0.4 & 0.3 & 0.1 & 0.1 & 0.1 \\
0.3 & 0.3 & 0.2 & 0 & 0.2
\end{array}\right]
$$

Single factor evaluation matrix of social benefits

$$
R^{2}=\left[\begin{array}{ccccc}
0.2 & 0.3 & 0.2 & 0.1 & 0.2 \\
0.3 & 0.2 & 0.2 & 0.2 & 0.1 \\
0 & 0.3 & 0.3 & 0.3 & 0.1 \\
0.4 & 0.2 & 0.1 & 0 & 0.3
\end{array}\right]
$$

Through the weight set of each index and the single factor evaluation matrix RI, the fuzzy comprehensive evaluation of the corresponding index can be obtained:

$$
\begin{gathered}
\mathrm{B}_{1}=\omega_{1} \times R^{1}=(0.2849,0.3347,0.2151,0.0543,0.111) \\
\mathrm{B}_{2}=\omega_{2} \times R^{2}=(0.2394,0.2546,0.1886,0.1226,0.1948)
\end{gathered}
$$

Considering the above evaluation results as a fuzzy comprehensive evaluation matrix B composed of multiple single-factor evaluation sets, the economic and social benefit evaluation is: $C=A \times B=(0.252,0.276,0.196,0.104,0.172)$.

\subsection{Value of Water Resources in Terms of Residents' Lives}

In 2018, the per capita disposable income of Golog Zang A.P was 14557 yuan, the per capita water consumption was about $66 \mathrm{~L}$ per day, and the cost and profit of tap water supply was $2.1 \mathrm{CNY} / \mathrm{m} 3$, maximum water fee bearing index is calculated as 0.03 .

Obtainable: $\quad \mathrm{P}=(0.03 \times 14557) \div(0.066 \times 365)-2=16.13 \mathrm{CNY} / \mathrm{m} 3, \quad$ Equal interval method, calculated price vector $S=\left[\begin{array}{llllll}16.13 & 12.0975 & 8.065 & 4.0325 & 0\end{array}\right]$. Through the calculation results, we can see that under the comprehensive influence of various factors, the price of domestic water in Golog Zang A.P is around 9.4 CNY $/ \mathrm{m} 3$. 


\section{Economic Value of Water Resources in Other Industries}

Calculate the value of water resources for irrigation crops, industry, construction and the tertiary industry by using the theory of emergy and the benefit sharing coefficient, the regional water resources' contribution to the economy can be obtained more accurately.

\subsection{System Emergy Calculation}

Emergy analysis theory and method was founded in the 1980 s by H.T. Odum, a famous American ecologist and pioneer of system energy analysis. Emergy is a new scientific concept and metric, defined as "the quantity of another form of energy contained in a kind of flowing or stored energy", or "the quantity of an efficiency that is directly and indirectly applied in the formation of products and services". Its essence is to include energy or embodied energy. Collect and organize the raw data of the research object about energy flow, material flow and money flow, distinguish and classify them, and calculate their energy.

Emergy calculation formula[16]:

$$
M=\tau \times B
$$

In the formula: $M$ represents the energy value (sej); $\tau$ represents the energy value conversion rate (sej/J or sej/g); B represents the energy or mass of the material ( $\mathrm{J}$ or $\mathrm{g}$ ).

Formula for calculating benefit sharing coefficient:

$$
\varepsilon=\frac{M_{i}}{\sum_{j=1}^{n} M_{j}}
$$

In the above formula: $M_{i}$ is the total energy value of the water supply; $M_{j}$ is the energy value of various inputs in the system; $\mathcal{E}$ is the benefit sharing factor.

\subsection{Irrigation Planting}

The formula for calculating the economic value of water resources for irrigation planting is[17], Precise data are shown in Table 4:

$$
\begin{aligned}
& E V W_{I \mathrm{r}}=T V W_{I r} / Q_{I r} \\
& T V W_{I r}=\varepsilon_{I, \mathrm{r}} \times \omega \times Y \times P
\end{aligned}
$$

In the formula: $E V W_{I \mathrm{r}}$ is the economic value of irrigation water resources $\left(\mathrm{CNY} / \mathrm{m}^{3}\right)$; $T V W_{I r}$ is the irrigation sharing benefit of the planting industry $\left(10^{8} \mathrm{CNY}\right) ; Q_{I r}$ is the irrigation water volume $\left(10^{8} \mathrm{~m}^{3}\right) ; \varepsilon_{I, \mathrm{r}}$ is the apportionment coefficient of crop irrigation benefits; $\omega$ is the planting area of crops $\left(\mathrm{hm}^{2}\right) ; Y$ is the average yield per year of crops with irrigation engineering $\left(\mathrm{kg} / \mathrm{hm}^{2}\right) ; P$ is the product price of crops $(\mathrm{CNY} / \mathrm{kg})$.

Table 4. Emergy analysis table of crop production system in Golog Zang A.P.

\begin{tabular}{ll}
\hline Project & Emergy conversion rate(sej/unit) \\
\hline Solar energy & 1 \\
Wind energy & 623 \\
Irrigation water & $1.74 \times 10^{12}$ \\
Agricultural machinery & $7.5 \times 10^{7}$ \\
Diesel oil & $6.6 \times 10^{4}$ \\
Nitrogen & $4.62 \times 10^{9}$ \\
\hline
\end{tabular}




\begin{tabular}{ll}
\hline Phosphate fertilizer & $1.78 \times 10^{10}$ \\
Potassium fertilizer & $1.74 \times 10^{9}$ \\
Compound fertilizer & $2.80 \times 10^{9}$ \\
Pesticides & $1.62 \times 10^{9}$ \\
Agricultural film & $3.8 \times 10^{8}$ \\
\hline
\end{tabular}

Note: (1) The original data are from the statistical yearbook. (2) The energy conversion rate and calculation formula are from the reference [18.19].

Table 5. Unilateral water value of irrigation planting in the research area.

\begin{tabular}{lll}
\hline Years & Coefficient & Unilateral water value $\left(\right.$ yuan $\left./ \mathrm{m}^{3}\right)$ \\
\hline 2009 & 0.51 & 18.77 \\
2010 & 0.485 & 15.24 \\
2011 & 0.486 & 20.46 \\
2012 & 0.45 & 22.06 \\
2013 & 0.43 & 25.73 \\
2014 & 0.41 & 28.04 \\
2015 & 0.38 & 28.99 \\
2016 & 0.44 & 33.15 \\
2017 & 0.39 & 40.89 \\
2018 & 0.38 & 39.28 \\
\hline
\end{tabular}

From Table 5, we can see that the value of local irrigation water is relatively high in recent years, reaching about $40 \mathrm{CNY} / \mathrm{m}^{3}$. The reason is that as the awareness of water resources increases and the application of drip irrigation technology changes the backward methods such as flood irrigation and string irrigation in the past. Avoiding water and soil loss and large amount of water evaporation, improving the efficiency of water resources utilization, and thus increasing the value of water resources.

\subsection{Industry, Construction and the Tertiary Industry}

The formula for calculating the economic value of water resources for industry, construction and the tertiary industry is [19], Precise data are shown in Table 6:

$$
\begin{gathered}
E V W_{S}=T V W_{S} / Q_{S} \\
T V W_{S}=B_{S} \times \varepsilon_{W, S}+F_{W, S}
\end{gathered}
$$

In the formula: $E V W_{S}$ represents the economic value of water resources of industry $\mathrm{S}$ (yuan $/ \mathrm{m} 3) ; T V W_{S}$ is the shared benefit of water withdrawal by industry $\mathrm{S}\left(10^{8} \mathrm{yuan}\right)$; $Q_{S}$ is the water withdrawal of industry $\mathrm{S}\left(10^{8} \mathrm{~m}^{3}\right) ; B_{S}$ is the total profit and tax of industry $\mathrm{S}\left(10^{4}\right.$ yuan $) ; \varepsilon_{W, S}$ is the benefit allocation coefficient of water withdrawal by industry $\mathrm{S} ; F_{W, S}$ is the complete water supply cost of industry( $\left.10^{4} \mathrm{yuan}\right)$

Table 6. Emergy analysis tables for production systems in other industries.

\begin{tabular}{ll}
\hline Project & Emergy conversion rate(sej/unit) \\
\hline Solar energy & 1 \\
Wind energy & 623 \\
Labor cost & $7.44 \times 10^{11}$ \\
Energy (equivalent to standard coal) & 39800 \\
Tap water & $3.89 \times 10^{13}$ \\
Surface water & $1.63 \times 10^{12}$ \\
Groundwater & $1.85 \times 10^{12}$ \\
Investment in fixed assets & $7.44 \times 10^{11}$ \\
\hline \multicolumn{2}{c}{ Note: (1) The original data are from the statistical yearbook. (2) The energy conversion rate and calculation } \\
formula are from the reference[20].
\end{tabular}


Table 7. Corresponding value of unilateral water in other industries in the study area.

\begin{tabular}{lllllll}
\hline years & $\begin{array}{l}\text { Industrial } \\
\text { efficiency } \\
\text { coefficient }\end{array}$ & $\begin{array}{l}\text { Unilateral } \\
\text { water value } \\
\text { (yuan/m3) }\end{array}$ & $\begin{array}{l}\text { Construction } \\
\text { industry } \\
\text { efficiency } \\
\text { coefficient }\end{array}$ & $\begin{array}{l}\text { Unilateral } \\
\text { water value } \\
\text { (yuan } / \mathrm{m} 3)\end{array}$ & $\begin{array}{l}\text { Tertiary } \\
\text { Industry } \\
\text { efficiency } \\
\text { Coefficient }\end{array}$ & $\begin{array}{l}\text { Unilateral } \\
\text { water value } \\
\text { (yuan } / \mathrm{m} 3)\end{array}$ \\
\hline 2014 & 0.064 & 24.58 & 0.04 & 26.89 & 0.078 & 21.66 \\
2015 & 0.07 & 15.39 & 0.02 & 13.96 & 0.073 & 36.84 \\
2016 & 0.068 & 22.12 & 0.027 & 25.11 & 0.074 & 39.02 \\
2018 & 0.06 & 26.86 & 0.026 & 25.27 & 0.067 & 40.23 \\
\hline
\end{tabular}

From the table 7 we can clearly see that the corresponding value of industrial unilateral water is between $15.39 \sim 26.86 \mathrm{CNY} / \mathrm{m}^{3}$, and the average value is around 22.9 $\mathrm{CNY} / \mathrm{m}^{3}$. The value of the construction industry is around $23.11 \mathrm{CNY} / \mathrm{m}^{3}$. The value of the tertiary industry is around $40 \mathrm{CNY} / \mathrm{m}^{3}$. We can see that the unilateral water efficiency corresponding to the service industry is the highest, which helps us to make reasonable industrial and water resource adjustments. Furthermore, improve people's living standards finally.

\section{Discussion}

According to the actual situation of the study area, this paper collects economic and social data in the study area, and uses fuzzy mathematics and emergy theory to calculate the value of its water resources. The entropy weight method is used to calculate the index weight, and the value of unilateral domestic water is calculated by using fuzzy mathematics method at about $9.4 \mathrm{CNY} / \mathrm{m}^{3}$. Based on emergy theory, the benefit sharing coefficients of other industries are calculated, and the unilateral water value of irrigation, industry, construction, and tertiary industry is around $37 \mathrm{CNY} / \mathrm{m}^{3}, 22.9 \mathrm{CNY} / \mathrm{m}^{3}, 23.11$ $\mathrm{CNY} / \mathrm{m}^{3}$, and $40 \mathrm{CNY} / \mathrm{m}^{3}$.

(1) There is a big gap between the calculation results of water resources value and the actual water price in the area. At this stage, the residents' water fee tolerance index is only $0.8 \%$, which is still a long way from the standard $3 \%$, Therefore, raising water prices will not have a big impact on the normal life of residents.

(2) There is a big gap between the water price and actual value of industrial and manufacturing industries and the tertiary industry, and the low water efficiency has caused the waste of regional water resources to a certain extent.

\section{Conclusions and Future Research}

The pricing method of water resources based on the traditional natural resource value theory cannot objectively and comprehensively interpret the value of water resources. The 
emergy analysis theory divides the energy flow, material flow and information that are not unified but closely related in the ecological economic system. The flow and currency flow are quantitatively analyzed using the common measure of emergy. This article uses emergy theory and fuzzy mathematics to quantitatively evaluate the value of regional water resources, discusses basic concepts and research methods, and proposes an emergy analysis and calculation model for regional water resources value evaluation, and combines the water resources of the Golog Zang A.P a case study was conducted.

The research results are consistent with the market value theory, indicating that the regional water resources value evaluation method based on emergy theory and fuzzy mathematics has a certain feasibility and scientific rationality, and can be used for the formulation and adjustment of regional water prices and the sustainable utilization of water resources. And optimized configuration provides a scientific theoretical reference.

However, considering the errors and incompleteness of the relevant data used in this research due to certain differences in survey and statistical methods, The calculation can only be simplified with the fixed value of the existing research results, coupled with the complexity of water resource value research and the application of emergy theory in resource value research is not yet mature. Therefore, the application of emergy theory and fuzzy mathematics to the quantitative evaluation of the value of regional water resources is only an attempt to study the value of water resources, and further research and improvement are needed.

\section{References}

[1] Zhu JL, Tao XY, Wang SJ, Wu JP. Measurement and Analysis of Water Resources Value in the Huaihe River Basin. Journal of Natural Resources. 2005; 20(1):126-131.

[2] He J, Chen XK. Calculation of shadow price of dynamic water resources in 9 river basins in China. Water Resources Economy. 2005; 23(1):14-19.

[3] Jiang WL. Water Resources Value Theory. Science Press, Beijing, 1998.

[4] Miao HY, Yang ZJ. Fuzzy comprehensive evaluation of regional water resources value. South-to-North Water Transfer and Water Conservancy Science and Technology. 2003; 1(15):17-19.

[5] Robert CJ. Micro and macro-level approaches for assessing the value of irrigation water. World Bank Policy Research Working, 2005, 3778.

[6] Glenn-Marie L, Rashid H. The economics of water management in southern Africa: An environmental accounting approach. Edward Elgar Publishing Limited, 2006.

[7] Pan X. Social and ecological accounting matrix: an empirical study for China. Int. Conf. IaO technique, 2009.

[8] Thorbeck. The use of social and ecological accounting matrices in modelling.26th Gen. Conf. Int. Assoc. for Research in Income and Wealth. Cracow, Poland, 2002.

[9] Krajnc D, Glavic P. A model for integrated assessment of sustainable development. Resources Conservation \& Recycling. 2005; 43(2):189-208.

[10] Ni JP, Ping L, Wei CF, Xie DT. Evaluation of Regional Land Development and Consolidation Potential Based on AHP and Entropy Weight Method. Journal of Agricultural Engineering. 2009; 25(05):202-209.

[11] Lu TC, Kang K. Application of Entropy Method and Analytic Hierarchy Process in Weight Determination. Computer Programming Skills and Maintenance. 2009; 22:19-20+53.

[12] Zadeh LA. Fuzzy sets. Information and Control. 1965; 8(3): 338-353.

[13] Wang WC, Xu DM, Chen SY, Qiu L. Research progress of variable fuzzy set theory and its application in water science. Advances in Water Conservancy and Hydropower Science and Technology. 2012; 32(05):89-94.

[14] Chen SY. Variable Set and Variable Set Principle and Method for Optimal Selection Decision of Water Resources System. Journal of Water Resources. 2012; 43(09):1066-1074.

[15] Zhang LW, Ding HF, Chen YJ. Railway Dangerous Goods Transportation Early Warning Based on Entropy Weight Fuzzy Comprehensive Evaluation. China Safety Science Journal. 2012; 22(05):119-125. 
[16] Ni HZ, Zhang CL, Chen GF, Zhao J, Feng L. Problems and Reform Suggestions of Water Supply Costs and Prices in China's Cities. Water Resources and Hydropower Engineering. 2019; 50(8):209-215.

[17] Tang JR. Economic Economics. Chemical Industry Press, Beijing, 2005.

[18] Odum HT. Environmental Accounting: Emergy and Environmental Decision Making. John Wiley \& Sons, New York, 1996.

[19] Buenfil AA. Emergy Evaluation of Water. Department of Environmental Engineering Sciences, University of Florida, Gainesville, U. S, 2001.

[20] Li LX, Gan H, Wang L, Ni HZ, Mu SM. Calculation and Analysis of Economic Value of Water Resources. Journal of Natural Resources. 2008; 3: 494-499. 